\title{
Simulação de um Processo de Produção para uma Linha de Produção de Blocos Vazados em uma Indústria de Cerâmica Vermelha com Auxílio da Ferramenta Arena
}

\author{
Gabriel Alexei Almeida Barros ${ }^{a *}$, José Antônio da Silva Souza ${ }^{b}$ \\ a Programa de Pós-graduação em Engenharia de Processos - PPGEP, Instituto de Tecnologia - ITEC, Universidade Federal do \\ Pará-UFPA, Belém, PA, Brasil \\ *e-mail: gabrielalexei.eng@gmail.com
}

\begin{abstract}
Resumo
No último decênio, a intensificação da competitividade presente no mercado impulsiona as empresas a voltarem o foco para o aprimoramento do sistema produtivo e políticas praticadas, buscando assim garantir o espaço ocupado pela concorrência. O objetivo principal deste trabalho é analisar o sistema produtivo de uma indústria cerâmica localizada na cidade de São Luís, MA e realizar o mapeamento dos processos produtivos juntamente com a aplicação do estudo de tempos e movimentos atrelado simulação computacional, para realização de um plano de otimização. O trabalho apresenta uma pesquisa exploratória aplicada, a partir do estudo de caso. Com a análise do fluxo de produção e a identificação das causas de perdas de eficiência, pode-se usar a ferramenta de simulação computacional para identificar as relações entre os processos e criar um plano de priorização para equipamentos-chave do processo produtivo. Conclui-se que, no sistema em estudo existem dois processos restritivos, máquina cortadora e forno lado b. Assim, com a identificação dos gargalos foi possível concentrar os esforços e investimentos nos pontos relevantes, tornando-a mais competitiva.
\end{abstract}

Palavras-chave: indústria cerâmica, simulação computacional, gargalos.

\section{Introdução}

À luz da globalização, o mercado se tornou mais rigoroso e menos flexível referente às empresas e organizações. Preço e qualidade adquiriram papel cada vez maior no campo da concorrência. A capacidade de agregar valor aos produtos com baixo custo, aliada à redução do lead-time e do tamanho dos lotes passaram a ser fundamentais para uma empresa se manter competitiva. Ficou evidente que uma seleção natural iria acontecer no mundo dos negócios (GOLDRATT; COX, 2002).

Diante disto, as organizações, sejam elas de pequeno, médio ou grande porte, necessitam de ferramentas de auxílio para permanecerem no mercado de constante alteração, não deixando se tornarem obsoletas e não competitivas. Gráfico do fluxo de processo, estudo de tempos e movimentos e simulação computacional, são ferramentas que permitem a análise "cirúrgica" de um sistema, facilitando o entendimento do mesmo bem como encontrar não conformidades e gargalos.

Pode-se considerar a existência de problemas em qualquer empresa, seja qual for o ramo de atuação, pois nenhum processo atua de maneira $100 \%$ confiável e livre de falhas. As ferramentas da engenharia de produção e operações podem ser usadas para constatar a solução destes problemas de maneira lógica e sistêmica. Mapear um processo, juntamente com o estudo de movimentos, tempos e simulação computacional tornaram-se recursos indispensáveis para o entendimento de um sistema produtivo e na solução de problemas frente a competitividade global.
O nicho mercadológico do setor ceramista no Brasil vem apresentando grande relevância nacional, com participação no PIB (Produto Interno Bruto) brasileiro de quase um por cento. (Associação Nacional da Indústria Cerâmica, 2005). Entretanto, a competitividade frente a outros países ainda é baixa, demonstrando a necessidade de modernização e melhorias deste segmento. A cerâmica vermelha é utilizada em diversos setores, como exemplo: tijolos para alvenaria estrutural, telhas, utilização em baldrames de fundações, tijolos para fornos, churrasqueiras e outros utensílios bastante utilizados e encontrados no cotidiano.

Para realização e aplicação do presente trabalho será feito um estudo de caso em uma indústria do setor ceramista vermelho, localizado no polo industrial da cidade de São Luís (MA). A empresa atua a 5 anos no mercado ludovicense, fabricando tijolos vazados e maciços. A mesma está buscando ampliar sua área de atuação, buscando aumentar o seu mercado consumidor na própria capital, almejando se estender para outros municípios. Assim, visando aumentar a lucratividade e torná-la mais competitiva, procurou-se medidas para proporcionar melhorias em seu processo produtivo.

O mapeamento de processos, atrelado a modelagem e simulação computacional auxilia a empresa a enxergar os pontos positivos e pontos negativos, que são: complexidade na operação, reduzir custos, gargalos, falhas de integração, atividades redundantes, tarefas de baixo valor agregado, 
retrabalhos, excesso de documentação e aprovações, além de ser uma excelente forma de melhorar o entendimento sobre os processos e aumentar a performance do negócio.

Portanto, a utilização do mapeamento de processos e simulação como ferramentas de análise e otimização dos processos de manufatura se apresentam como métodos de grande eficiência para detalhar e buscar sanar alguns desperdícios existentes, sendo um grande aliado na solução de problemas que limitam a competitividade da empresa.

\section{Método}

A simulação nos últimos anos se tornou um dos métodos mais eficientes para a tomada de decisões com rapidez e lógica matemática, reduzindo as incertezas presente no empirismo e nas experiências dos profissionais e especialistas. Fazendo com que seja possível a análise de várias alternativas que o sistema em estudo pode enfrentar, possibilitando uma melhor compreensão do sistema real minimizando necessidade de gastos com recursos (PRADO, 2003).

\subsection{Simulação computacional}

A simulação pode ser conceituada de diversas formas, dependendo da importância desse método para cada autor. Porém, todos são unânimes em defender a simulação como um método útil para resolução de problemas de sistemas complexos. A seguir, é mostrado o conceito sobre a visão da literatura especializada.

Para Lorenço (1981), a simulação é uma aproximação na qual as características, a forma e a aparência do sistema em estudo são imitadas com o fim de executar experiências substitutas. É a representação de um sistema real através da réplica de uma sucessão de eventos que têm lugar no sistema, de acordo com relações matemáticas e decisões lógicas, permitindo que se efetue a experimentação, sem que tal necessite ser feita no mundo real. A simulação permite imitar o funcionamento de um sistema real, com o auxílio de softwares em computadores é possível visualizar na tela o funcionamento do sistema em estudo, tal como um filme. Segundo Prado (2014), simulação é uma técnica de solução de um problema pela análise de um modelo que descreve o comportamento do sistema, usando um computador digital. Isto permite a reprodução do funcionamento de um sistema, com auxílio de um modelo, que nos permite testar algumas hipóteses sobre o valor das variáveis controladas.

Na visão de Swait (1987), a simulação é um procedimento em que um modelo matemático computacional de um sistema físico é utilizado para efetuar experimentos sobre o sistema através da geração de estímulos externos e da observação das reações do sistema durante um período de tempo. Talvez seja a única técnica que analisa problemas onde ocorrem variações pronunciadas da demanda ao longo do tempo. A simulação é uma técnica disponível para modelagem de sistemas, bem como a teoria das restrições, no trabalho em estudo irá fazer uso desta ferramenta, simulação, para auxiliar no estudo da indústria cerâmica.
A simulação possui grande relevância, pois permite ao engenheiro, realizar estudos sobre correspondentes sistemas modelados para responder questões como exemplo: "O que aconteceria se?”. A principal importância é que tais questões podem ser solucionadas e respondidas sem que os sistemas reais sob investigação sofram qualquer perturbação, uma vez que os estudos são feitos no computador.

Outra grande vantagem da simulação computacional é obter a resposta sobre essas perguntas antes de se ter o sistema real funcionando, e com grande confiabilidade. (FREITAS FILHO, 2008). Segundo Fernandes et al., (2006), a utilização da técnica de simulação auxilia e possui grande importância nos seguintes aspectos: 1) projetar e analisar sistemas industriais; 2) prever resultados na execução de determinada ação; 3) reduzir os riscos na tomada de decisão; 4) identificar problemas antes de suas ocorrências; 5) eliminar procedimentos em arranjos industriais que não agregam valor à produção; 6) realizar análises de sensibilidade; 7) reduzir custos com o emprego de recursos (mão de obra, energia, água e estrutura física); e 8) revelar a integridade e viabilidade de determinado projeto em termos técnicos e econômicos. Os aspectos citados anteriormente demonstram os principais fatores que podem ser analisados com a utilização desta ferramenta. Para Law e Kelton (2000) a simulação permite uma visão sistema mais precisa e de fácil entendimento, permitindo com que o engenheiro perceba como alterações especificas locais podem alterar no sistema global.

\subsection{Linhas de produção}

Este é um setor no qual, a modelagem e simulação possuem uma vasta e maior aplicabilidade. Vários cenários se encaixam neste item, desde empresas manufatureiras até empresas prestadoras de serviços. Segunda Prado (2014), um setor de produção pode ser planejado, verificando gargalos e obtendo um melhor fluxo dentro dele. Além disso, modificações em modelos já existentes, seja pela necessidade de aumentar a produção ou pela troca de equipamentos ou adição de novos produtos. Com a simulação consegue-se informar onde deverão ser feitas as modificações necessárias para adequar o processo da melhor maneira possível, chegando assim, após algumas tentativas, ao melhor modelo requerido.

Também, melhores políticas de estoques podem ser obtidas, como exemplo: solicitação de material, atendimento pelos fornecedores, como evitar com que determinada matéria prima não falte e prejudique todo o processo, uma infinidade de atribuições.

\subsection{Principais elementos da simulação}

Em um modelo computacional de simulação existem diversos elementos ou termos. Segundo Freitas Filho (2008) os elementos são os seguintes:

- Variáveis de Estado - são valores que determinam o estado do sistema, elas constituem um conjunto de informações necessárias à compreensão do que está ocorrendo no sistema num determinado instante do tempo em relação ao objeto de estudo. 
A determinação dessas variáveis é o propósito do estudo;

- Eventos - são acontecimentos, ocorrências, programadas ou não, os quais provocam uma mudança de estado em um sistema. A ocorrência de um evento resulta na alteração de pelo menos uma variável de estado;

- Entidades - são elementos essenciais para o funcionamento do modelo. As entidades podem ser objetos ou pessoas que na maioria das vezes possuem um ciclo de vida dentro do sistema. As entidades são classificadas como dinâmicas, que entram no sistema, participam dos processos, ou seja, seu ciclo de vida, e abandona o sistema, alguns exemplos de entidades dinâmicas são: peças (que se movem pela fábrica), pacientes chegando a um hospital e saindo depois do atendimento, pessoas em filas de bancos, supermercados, paradas de ônibus dentre outros. As estáticas são entidades que executam suas funções sem abandonar o sistema, alguns exemplos são: máquinas que realizam processos mecânicos, um atendente de banco, um médico, um ônibus. Em relação às entidades dinâmicas suas chegadas são realizadas por um procedimento externo, que pode ser aleatório ou definido. Quando a entidade entra em um processo ela, na maioria das vezes, requer recursos (matéria-prima, tempo, mão de obra) que depois de processados, são removidas do processo;

- Atributos - são as características próprias das entidades, no ponto de vista prático os atributos são meios de armazenamento de valores relacionados a uma entidade especifica. Os atributos são de grande importância para a análise do sistema, pois a partir dos mesmos podem ser feitas investigações sobre vários tipos de entidades, alguns exemplos de atributos são: um código presente em uma peça, o formato ou tamanho de uma matéria-prima, entre outros;

- Recursos - são entidades estáticas que fornecem serviços para entidades dinâmicas. Um recurso pode ter capacidade de servir uma ou mais entidades dinâmicas ao mesmo tempo, operando em servidores paralelos, como também é possível que uma entidade dinâmica opere com mais de uma unidade de recurso ao mesmo tempo ou com diferentes recursos simultaneamente, caso uma entidade não consiga ser servida por um recurso é porque o mesmo está ocupado e a mesma deverá aguardar por ele em uma fila;

- Filas de Recursos - são locais de espera onde as entidades dinâmicas esperam sua vez de seguir através do sistema. O processamento de um fila depende exclusivamente das políticas operacionais adotadas no sistema ou modelo que a representa. As políticas utilizadas são: FIFO "First In, First Out", onde o primeiro a chegar à fila será o primeiro a ser atendido pelo recurso, LIFO "Last In, First Out", o último a entrar é o primeiro a sair, HVF "High Value First", o maior valor primeiro, LVF "Lower Value First", o menor valor primeiro, ou algum critério pré-estabelecido;

- Atividades - são sequências de procedimentos que causam mudanças no sistema. À atividade corresponde a um período de tempo pré-determinado, que também pode ser chamado de estado ativo, que é comum a uma ou mais entidades. A duração de uma entidade pode ser determinística ou estocástica. Uma atividade é indivisível, ou seja, uma vez iniciada ela não pode ser mais interrompida. Um exemplo de atividade é o atendimento em caixa de um banco, o atendimento a um cliente A dura $20 \mathrm{~min}$, e de um cliente B dura $17 \mathrm{~min}$, ou seja, essa atividade é representada por uma distribuição de probabilidade;

- Períodos de Espera - são tempos sobre os quais não se tem controle se o modelo contiver variáveis aleatórias. Um exemplo é caso uma peça que entre na fila de espera para o processamento em um torno, o período de espera será a soma dos tempos dos processamentos de todas as peças que chegaram à fila antes da mesma;

- Tempo Real e Tempo de Simulação - o Tempo Real consiste no tempo que o sistema real estaria em funcionamento e o Tempo de Simulação é o período de tempo que o modelo simula o sistema real. Alguns exemplos caracterizam melhor a diferenças desses dois tipos de tempo. Eles são: O processamento de informações em um computador, no tempo real as informações são movimentadas em milissegundos e o tempo de simulação dura minutos ou até horas. Já em um processo de simulação de uma fábrica cerâmica, o tempo real pode ser dias, semanas ou até meses e o tempo de simulação o representa em horas;

- Acumuladores - são variáveis do modelo, que acumulam valores que permitem medir o desempenho do sistema. Essas variáveis acumulam valores com o tempo, para depois receberem tratamento de análise e gerar as estatísticas de simulação;

- Relógio - é uma variável que acumula o tempo real ou simulado do sistema, diferenciando-se, assim, do tempo de simulação;

- Cenário - é uma experimentação de configurações pré-estabelecidas do sistema real. Os cenários possuem variáveis, entidades e dados alterados para análise dos sistemas;

- Aquecimento - é um período de tempo que as estatísticas geradas são expurgadas, pois não representam o sistema em questão devido à variação excessiva; 
- Replicação - é a execução do modelo computacional. Representa o período de

Tempo de início e fim de um ciclo de eventos de simulação.

\subsection{Modelagem e simulação utilizando o software ARENA}

Segundo Prado (2003), o ARENA é um sistema de simulação para eventos discretos, que analisa os processos existentes em um sistema. O ARENA utiliza uma interface gráfica para usuário denominada GUI, que significa Graphical User Interface, que otimiza o acesso do usuário à ferramenta.

Esse software foi desenvolvido pela empresa Systems Modeling, no ano de 1993, como sucessor do SIMAN (primeiro software de simulação para computador) e CINEMA, os quais foram desenvolvidos em 1982 e 1984, respectivamente. Em 1984, o SIMAN recebeu um complemento chamado CINEMA (primeiro software de animação para computador), sendo posteriormente melhorado e, a partir de 1993, os dois programas foram unificados e aperfeiçoados em um único software, o ARENA. Em 1998, a empresa Rockwell Software incorporou a Systems Modeling.

O funcionamento do ARENA se dá com um conjunto de blocos (ou módulos) que são utilizados para descrever uma aplicação real. Esses funcionam como códigos de programação descrevendo as relações das variáveis do processo e suas interações. Além de permitir a construção de modelos de simulação, o software em questão possui ferramentas de análise de dados de entrada (Input Analyser) e análise de resultados (Output Analyser), que serão responsáveis pela representação das distribuições de probabilidade que alimentaram o modelo, como também a análise estatística dos resultados gerados.

Para a utilização das amostragens extraídas no processo, o ARENA não avalia cada número individualmente e sim trabalha com curvas estatísticas, podendo deste modo chegar mais perto ao comportamento real do sistema. Assim, de acordo com Freitas Filho (2008), esta ferramenta computacional tem o propósito de auxiliar no tratamento dos dados amostrais brutos, buscando avaliar as melhores opções para as distribuições de probabilidades que serão empregadas. O principal propósito do Software ARENA é a identificação da distribuição teórica de probabilidades por meio de testes de aderência, realizando um tratamento na coleta de dados do sistema real. É importante ressaltar que isso é realizado através de testes de aderência.

Ainda segundo Freitas Filho (2008), depois de coletadas as amostras do sistema real deve-se inseri-los no ARENA, de acordo com a distribuição dada, realizam-se testes de aderência Chi-Quadrado e Kolmogorov-Smirnof (K-S) para validar esses dados como representativos do sistema real. Nos testes de aderência admite-se por hipótese, que a distribuição da variável de interesse na população seja descrita por um determinado modelo de distribuição de probabilidades e se testa o modelo, ou seja, verifica-se a boa ou má aproximação dos dados da amostra ao modelo.

\section{Resultados Obtidos}

O modelo foi executado com a quantidade de replicações e por um período de um mês de simulação (30 dias) obtendo o seguinte resultado para o indicador principal, conforme apresentado na figura 1 abaixo.

A figura 1 anterior, mostra que a fábrica conseguiu produzir durante um período de trinta dias (um mês) de trabalho o equivalente a 240 mil tijolos, indicado como number out, valor este equivalente aos relatórios reais feitos pelo setor de produção da fábrica. O software ARENA após a realização da simulação gera um relatório que permite de acordo com os dados da modelagem identificar o(s) gargalo(s) do processo, bem como o tempo de atravessamento e filas existentes, permitindo assim a identificação da restrição do sistema.

Conforme o resultado gerado, verificou-se que os gargalos existentes no processo produtivo são dois: Etapa de Corte e Forno B. Como apresentado no gráfico 1 a seguir, resultado da simulação computacional.

O gráfico 1 anterior, mostra parte do relatório de simulação gerado pelo software ARENA que sinaliza duas restrições existentes, que são na etapa do processo corte dos tijolos e no processo de queima do forno B. Como pode-se verificar a etapa de corte está trabalhando com uma taxa de utilização de $100 \%$ (por cento), já os demais recursos possuem uma taxa de utilização bem menor, com exceção do segundo gargalo encontrado, forno B, que possui uma taxa de utilização de $90 \%$ e, além disso, está ocasionando o maior número de filas no processo, gerando estoques intermediários.

Para realizar a correta identificação dos gargalos no sistema e interpretação do relatório gerado na simulação, deve-se levar em consideração algumas premissas. Segundo Goldratt e Cox (2002), um gargalo é todo recurso que restringe a capacidade do sistema, no livro A Meta isso pode ser exemplificado no capítulo em que o protagonista acompanha uma equipe de jovens escoteiros e faz uma analogia dessa situação com um determinado sistema produtivo. Percebe-se que na trilha existe um garoto acima do peso (processo) com eventos dependentes combinados com flutuações estatísticas próprias e capacidade inferior dos demais. Assim, por mais que os outros escoteiros (demais processos) busquem caminhar de forma rápida, quem irá ditar o ritmo da caminhada será o garoto acima do peso, gargalo encontrado, caso contrário o inventário

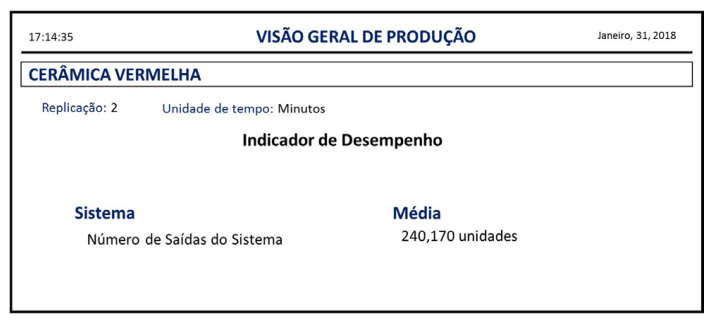

Figura 1. Quantidade de tijolos fabricados - período de um mês. Fonte: Gerado pelo Software ARENA. 


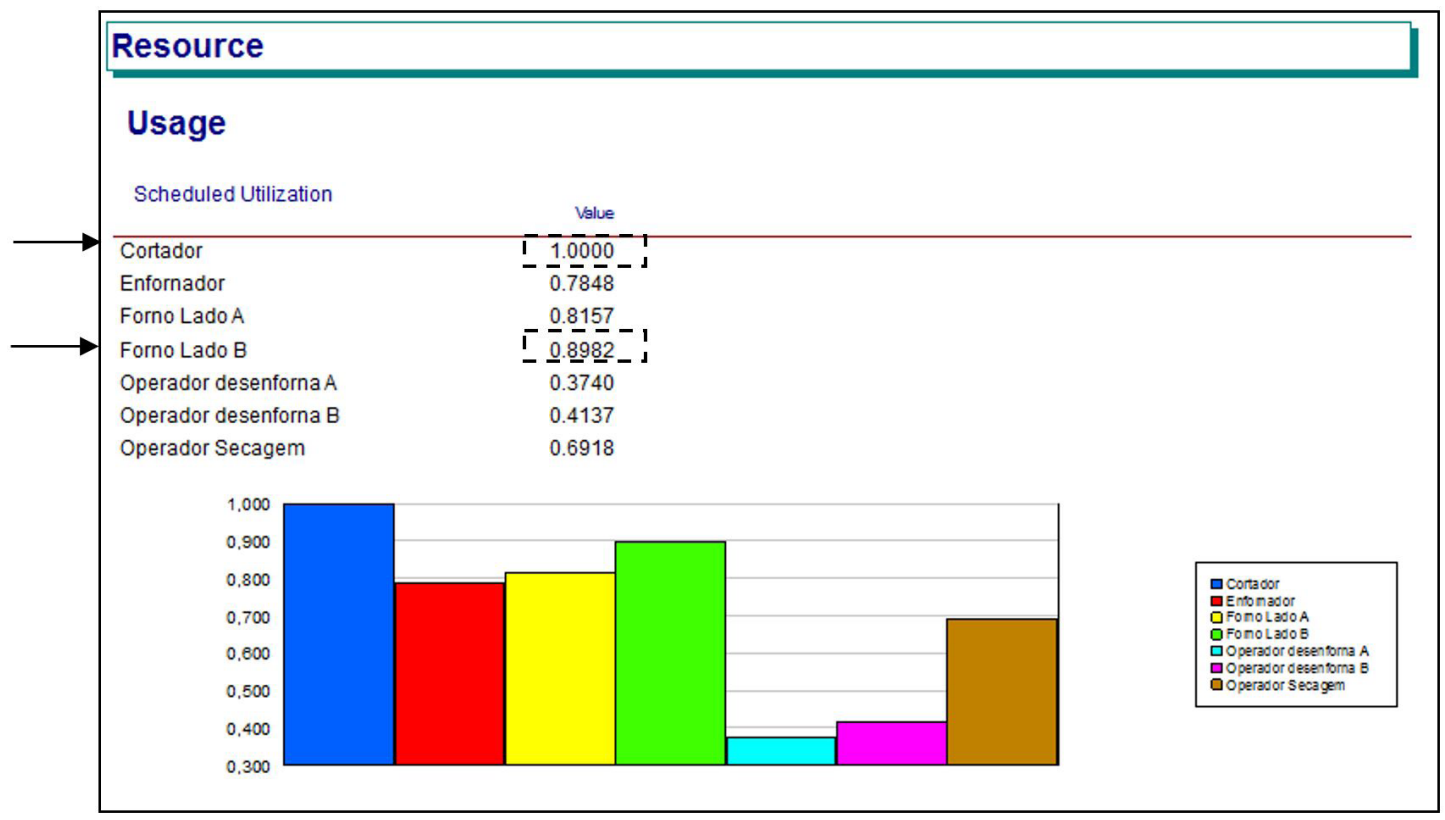

Gráfico 1. Dados do Output Arena- Informa a taxa de utilização dos recursos.

referente ao processo irá aumentar, o ganho irá cair e a despesa operacional provavelmente subirá.

Levando o mesmo exemplo para o lado industrial, quando se tem um gargalo no sistema, as atenções devem estar voltadas em como melhorar a capacidade desta restrição, que no caso da trilha de escoteiros a solução encontrada foi colocar o garoto acima do peso na frente da fila e retirar o peso em excesso que o mesmo carregava em sua mochila. "Uma hora perdida no gargalo é uma hora perdida no sistema inteiro" (GUERREIRO, 1999)

Assim, o primeiro gargalo identificado no processo encontra-se na etapa de corte, o mesmo para atender a demanda de produção atua com sua capacidade máxima, ditando o ritmo em todo o restante do processo, e mesmo assim os processos subsequentes possuem capacidade de atender uma demanda maior de tijolos.

Isso ocorre devido à quantidade de peças que são fabricadas com algum tipo de defeito. Observa-se também que de acordo com a análise dos dados reais e comprovada na simulação, na etapa de empilhamento dos tijolos e retirada dos tijolos da esteira, há um percentual de refugo de aproximadamente 20\% (por cento) das peças. Essas perdas são causadas por pedaços de raízes, pregos e pequenas pedras que agarram na matriz da extrusora, provocando defeito no tijolo na etapa de corte subsequente. A falta de qualidade no processo de preparação da matéria-prima e manutenção nas máquinas são os principais motivos das perdas. Dessa forma, para suprir as necessidades de produção este equipamento acaba trabalhando em ritmo intenso. É importante lembrar que "utilização e ativação de um recurso não são sinônimos", e que a gerência deve estar consciente de que o sistema só pode produzir até a capacidade do recurso restritivo, e que a utilização de capacidades superiores a este nível irá gerar estoques em processo desnecessários (caracterizando um capital investido em locais que não trarão retorno). (GUERREIRO, 1999).

A Tabela 1 a seguir, faz parte também de uma das páginas geradas pelo relatório da simulação realizado. Gerando outro indicador que é de grande relevância para o presente estudo, quantidade de filas existentes dentro do processo, indicando os valores máximos de tijolos (Maximun Value), a quantidade mínima de tijolos (Minimun Value) e o Avarage, que é o valor médio de filas ocasionadas em cada processo, ou peças que estão em espera.

Na tabela 1, pode-se verificar que o maior causador de filas no processo é o forno lado B, gerando o equivalente médio de 14.981 (quatorze mil novecentos e oitenta e um) tijolos em estoque intermediário, esperando para serem queimados. Sendo assim o segundo gargalo encontrado. De acordo com o guru da indústria, um gargalo também pode ser conceituado como. "Um gargalo é qualquer recurso cuja capacidade é igual ou menor que a demanda de mercado imposta sobre ele". (GOLDRATT; COX, 2002, p. 152). O surgimento de grande quantidade de estoques intermediários neste processo (Forno B) caracteriza que mesmo ele atuando com uma capacidade alta de $90 \%$, ele não está atendendo a demanda imposta sobre ele.

Outro resultado de grande relevância encontrado na simulação computacional foi o tempo de atravessamento médio entre pallets conforme apresentado abaixo na tabela 2. É possível perceber que o lead time entre pallets encontra-se como valor médio de 20 minutos (Média).

De posse desses resultados é possível propor melhorias, concentrando o plano de otimização nos gargalos encontrados, que como citado anteriormente são as restrições principais do processo. 
Tabela 1. Relatório Gerado pelo software Arena - filas (QUEUE) existentes no processo.

\begin{tabular}{|c|c|c|c|c|}
\hline \multicolumn{5}{|c|}{ FILAS } \\
\hline \multicolumn{5}{|c|}{ TEMPOS } \\
\hline Tempos de Espera & Média & Meio & Valor Mínimo & Valor Máximo \\
\hline Lote 1 - Agrupa Pallets 460 tijolos. (Fila) & 11.546 & 4,6 & 0 & 3785 \\
\hline Lote 2 - Agrupa Tijolos para o Forno. (Fila) & 2.143 & 0,8883 & 0 & 3785 \\
\hline Lote 3-Agrupa 236 Pallets Queima. (Fila) & 424.70 & Correlacionado & 0 & 1325 \\
\hline Lote 4 - Agrupa 224 Pallets Queima. (Fila) & 643.19 & 195,29 & 0 & 4392 \\
\hline Cortador esta livre? (Fila) & 0.35 & 0,1088 & 0 & 3780 \\
\hline Processo 1 - Cortador (Fila). & 0 & 0 & 0 & 0 \\
\hline $\begin{array}{l}\text { Processo } 2 \text { - Tempo de Descarregamento de } \\
\text { Pallets Secagem - (Fila) }\end{array}$ & 3.249 & 3,97 & 0 & 3779 \\
\hline $\begin{array}{l}\text { Processo } 3 \text { - Empilhamento Pallets Forno. } \\
\text { (Fila) }\end{array}$ & $1.792,85$ & Correlacionado & 610 & 3604 \\
\hline $\begin{array}{l}\text { Processo } 5 \text { - Empilhar Pallet para estocagem } \\
\text { (Fila). }\end{array}$ & $2.014,06$ & 580,46 & 225 & 5168 \\
\hline $\begin{array}{l}\text { Processo 6- Empilhar Pallet para Estocagem. } \\
\text { (Fila). }\end{array}$ & $2.168,41$ & Correlacionado & 569 & 5094 \\
\hline Captura 2 - Queima lado A & 0 & Insuficiente & 0 & 0 \\
\hline Captura 3 - Queima lado B & $14.981,49$ & Insuficiente & 0 & 28563 \\
\hline
\end{tabular}

Fonte: Software ARENA.

Tabela 2. Relatório Gerado pelo software Arena - Tempo de Atravessamento médio entre Pallets.

\begin{tabular}{cccc}
\hline \multicolumn{4}{c}{ Tempo de Atravessamento } \\
\hline \multicolumn{4}{c}{ CONTAGEM } \\
\hline Entre & Média & Valor Mínimo & Valor Máximo \\
Registro 1 - Tempo entre Pallets & 204.695 & 46.420 & 3785.25 \\
\hline
\end{tabular}

Fonte: Software ARENA.

\section{Conclusão}

Como objetivo final deste estudo, a elaboração do plano de otimização do processo de fabricação de blocos cerâmicos, buscou-se conceder à empresa uma ferramenta para guiar-se pelas melhores formas de otimizar a produção e investir o capital disponível nos locais certos.

A simulação atrelada a ferramentas de tempos e métodos, possibilitam a avaliação de restrições em um sistema, como pode ser comprovado no tópico anterior e ao decorrer deste trabalho. Diante das análises realizadas e levantamento dos gargalos existentes, propomos melhorias para minimizar os problemas encontrados no processo de produção:

- A $1^{\text {a }}$ (primeira) causa encontrada que prejudica o funcionamento da restrição, máquina de extrusão e corte, é devido a presença de materiais contaminantes, como exemplo: pregos, raízes, pedras, dentre outros objetos sendo metálicos ou não, na argila em processo.

- A2 (segunda) causa observada, é que a quantidade de água adicionada a mistura é feita de forma aleatória e visual, acarretando na granulometria da argila, ficando quebradiça, esfarelada, aumentando os tijolos em refugo, pois além de não adquirirem consistência após a etapa de extrusão, acabam trincando na etapa de queima, impossibilitando utilização.

- Como $3^{\mathrm{a}}$ (terceira) causa, verifica-se que a inspeção visual da argila é feita após a etapa de corte, ou seja, muitas vezes a cortadora executa seu trabalho em tijolos defeituosos que iram para refugo, ocasionando tempo perdido.

- Como 4a (quarta) causa relevante, observa-se que os tijolos em refugo são colocados na extrusora novamente.

Estas causas levantadas interferem no elemento restritivo encontrado 1 (extrusora e cortadora) de forma acentuada e consequentemente em todo o restante da cadeia. Gerando quatro consequências negativas ao processo em análise, sendo verificado a seguir.

$\checkmark$ Diminuição na confiabilidade do processo de Extrusão e Corte (gargalo 1);

$\checkmark$ Diminuição na qualidade final do produto; 
$\checkmark$ Aumento na quantidade de refugo;

$\checkmark$ Aumento no tempo de empilhamento dos pallets.

Levando em consideração o primeiro gargalo identificado, processo de extrusão e cortador, as causas e consequências anteriormente definidas, serão levantados adiante as possíveis soluções, para esta restrição.

Desta forma, com o objetivo de minimizar os problemas anteriormente encontrados e consequentemente ajudar na performance do gargalo, uma das medidas tomadas neste primeiro evento de melhoria é a utilização de um extrator de sucata.

Posicionado a alguns centímetros acima das correias transportadoras. O extrator de sucata permite a retirada de objetos ferrosos com a utilização de um circuito magnético suspenso com imãs, minimizando a contaminação da argila e a proteção de equipamentos contra quebras geradas por estes objetos. A figura 2 a seguir permite o melhor entendimento desta melhoria.

Segundo a INBRAS (2015), o separador eletromagnético (Extrator de Sucata) foi desenvolvido para retirar sucatas ferrosas das correias transportadoras, com o objetivo de retirar sucatas ferrosas do produto final, evitar embarque de material não conforme para outra etapa do processo, evitar acidentes com sucatas ferrosas durante os processos de produção, evitar quebras de equipamento, aperfeiçoar o rendimento do processo.

Além disso, possui pontos positivos que favorecem sua aplicação: não requer consumo de energia elétrica, não há existência de óleo refrigerante, pois não ocasionam aquecimento, não precisa de painel de controle e não possuem riscos de incêndio nem explosão.

Outra solução proposta é a criação de uma pequena unidade laboratorial para fazer testes granulométricos e de amostragens. Permitindo a observação das composições físico-químicas da argila, além de amostragens para verificação de contaminantes não metálicos.

Com relação a inspeção de qualidade visual, como relatado acima, a mesma é feita após a etapa de corte, no segundo evento de melhoria essa inspeção atuará em três pontos focais. Na entrada da matéria prima ao sistema, antes

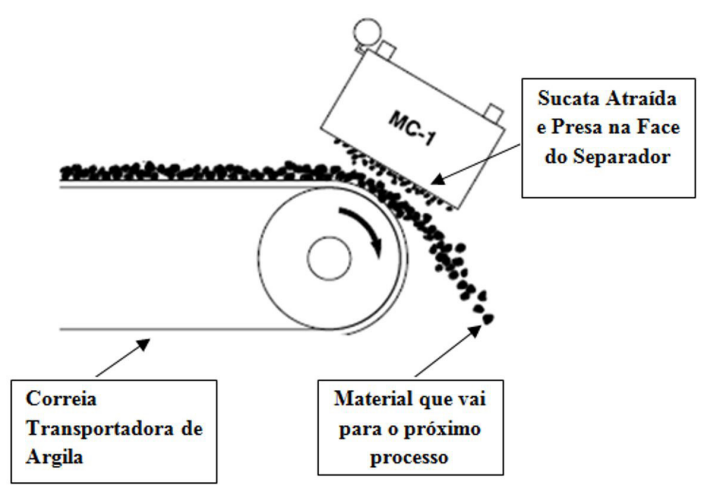

Figura 2. Representação do funcionamento de um Extrator de Sucata. Fonte: Manual Técnico da INBRAS (2015). do processo de extrusão e após a queima dos tijolos. Pois o tempo perdido confeccionando peças com defeito, que vão para refugo, gera atraso em todo o sistema. Assim, a inspeção visual dividida nestes pontos focais, permite em conjunto com o primeiro evento de melhoria, encontrar objetos que ocasionam inconformidades no produto e atraso na produção.

Além disso, percebe-se que o grande número de peças refugadas após a etapa de corte, ocasionam atraso no processo de empilhamentos dos pallets que vão para secagem. Pois os dois funcionários da esteira responsáveis por este processo, acabam tendo que interromper seu trabalho para ajudar o inspetor visual a retirar os tijolos para refugo. Assim estes eventos de melhorias permitem diminuir a quantidade de tijolos para refugo, ajudando na operação de empilhamento também.

Verifica-se que as peças que sofrem refugo retornam diretamente ao processo de extrusão. Isso provoca lentidão na produção, uma vez que as peças não passam pelo processo de homogeneização. Como terceiro evento de melhoria, os tijolos que sofrem retrabalho iram retornar ao ponto inicial do processo, caixão alimentador, com o objetivo de homogeneizar novamente o material e deixar a argila em condições ideais de extrusão e corte.

Como explanado no começo deste capítulo, os eventos de melhorias anteriores tiveram foco principal no gargalo 1 encontrado, máquina de extrusão- corte. A seguir será explicado o quarto evento de melhoria, focando-se no segundo gargalo identificado, forno lado B.

Verifica-se que o forno lado B está formando uma grande quantidade de filas, ocasionado estoques intermediários no processo. Como possíveis causas desta restrição, tem-se:

$\checkmark \quad 1^{\text {a }}$ (primeira) causa, é devido à falta de sinalização no processo de empilhamento para queima e identificação de qual forno está livre;

$\checkmark 2^{\text {a }}$ causa identificada, verifica-se que a capacidade do forno lado B é menor que do forno lado A;

$\checkmark 3^{\text {a }}$ terceira causa identificada observa-se a falta de manutenções preventivas nos fornos.

Como pode ser comprovado nos resultados da simulação, as causas anteriores citadas, ocasionam dois problemas principais na segunda restrição encontrada, forno lado B. Sendo exposto a seguir.

$\checkmark$ Formação de Filas no processo de queima (estoques intermediários)

$\checkmark$ Aumento no lead time do processo

Será levantado adiante as possíveis soluções, para esta restrição, caracterizado como quarto evento de melhoria

Criação de um controle de critérios de alocação de capacidade, verifica-se que o forno lado B está formando uma grande quantidade de filas, ocasionado estoques intermediários no processo. Com a criação de um sistema de sinalização, consegue-se ter uma maior precisão neste ponto da fabricação, sinalizando qual linha estará livre 
para desenforna e enforna. Como forma de controlar o volume dos estoques em processo, a implantação de pulmões de recurso, se faz necessário, com o objetivo de auxiliar no controle de produção.

Cox e Spencer (2002, p.124) afirmam que:

A restrição é o tambor, e o pulmão é a quantidade física de estoques estrategicamente posicionados para manter a restrição operando, absorvendo as instabilidades normais do processo de produção nas operações que o antecedem. A corda é um dispositivo de comunicação a partir da restrição até a operação de entrada que dispara a liberação de material adicional para a fábrica.

O pulmão é formado através da liberação antecipada de materiais para o sistema, que leva ao acúmulo de materiais ou produtos acabados aguardando pelo futuro processamento ou expedição. O tamanho dos pulmões é definido em função da variabilidade e capacidade existente nos processos que compõem o sistema.

Desta forma, um sistema de sinalização correta na linha de produção, ajudaria os funcionários a terem um maior controle nesta etapa de restrição, otimizando a performance do gargalo.

O aumento da confiabilidade também se faz necessário para a intermitente operação do processo restritivo, garantindo assim que problemas mecânicos influam o mínimo possível na capacidade produtiva. Sendo assim, um plano de manutenção preventiva atualizado deve ser elaborado com base nos manuais e em recomendações dos fabricantes.

A manutenção preditiva também deve fazer parte da rotina dos operadores, de modo a assegurar que os problemas em potencial sejam identificados antes que aconteçam. Desta forma, os responsáveis devem ser treinados a executar vistorias e inspeções regulares com o propósito de reconhecer adversidades em tempo hábil para executar ajustes e reparos sem que haja a necessidade de parada das máquinas.

Como último evento de melhoria, temos a implantação de termostatos. A função do termostato é impedir que a temperatura de determinado sistema varie além de certos limites preestabelecidos. Um mecanismo desse tipo é composto por dois elementos: um indica a variação térmica sofrida pelo sistema e é chamado elemento sensor, o outro controla essa variação e corrige os desvios de temperatura, mantendo-a dentro do intervalo desejado. São utilizados em vários segmentos, inclusive na indústria cerâmica para controle das temperaturas internas dos fornos.

Com a implantação de termostatos em locais específicos nos fornos, pode-se controlar a temperatura interna e ter um controle maior da temperatura. Facilitando o controle do tempo de queima mais preciso dos tijolos. Diminuindo assim tempo de queima ocioso, ocasionando formação de filas e/ou falhas na composição dos tijolos.

Estas são as propostas de melhorias sugeridas ao proprietário da empresa em estudo, que aplicadas de forma correta ocasionarão na otimização do recurso gargalo e consequentemente no processo produtivo global.

\section{Referencias}

ASSOCIACAO NACIONAL DA INDUSTRIA CERAMICA. - Telhas cerâmicas cobrem o Brasil - Normas técnicas estimulam novos modelos, controle de qualidade e maior informação ao consumidor. Revista da Anicer, Associacao Nacional de Ceramica Vermelha ABC, 2010.

BARNES, Ralph M. Estudo de movimentos e de tempos: projeto e medida do trabalho. São Paulo: Editora Edgard Blücher, 2001.

BATALHA, Mário Otávio. Introdução à Engenharia de Produção. Rio de Janeiro: Elsevier, 2008.

BAZZO, Walter Antonio; PEREIRA, Luiz Texeira do Vale. Introdução a Engenharia: conceitos, ferramentas e comportamentos. Florianópolis: UFSC, 2008.

CAMPOS, Vicenti Falconi. TQC: controle da qualidade total. 1992.

CORRÊA, Henrique L.; CORRÊA, Carlos A. Administração de Produção e Operações. São Paulo: Atlas, 2004. 690 p.

COX, James F; SPENCER, Michael S. Manual da teoria das restrições. Tradução Fernanda Kohmann Dietrich. Porto Alegre: Bookman, 2002.

ESCRITÓRIO Técnico de Estudos Econômicos do Nordeste ETENE. Informe Setorial Cerâmica Vermelha, out./2010.

FERNANDES, Luís César da et. al. Simulação da dinâmica operacional de uma linha industrial de abate de suínos. Disponível em: Http://Www.Scielo.Br/Pdf/Cta/V26n1/28866.Pdf

FREITAS FILHO, Paulo José de. Introdução à modelagem e simulação de sistemas com aplicações em Arena. Florianópolis: Visual Books, 2008.

FONSECA, Jairo Simon da; MARTINS, Gilberto de Andrade. Curso de Estatística. São Paulo: Atlas, 2009.

GAVIRA, Muriel de Oliveira. Simulação computacional como uma ferramenta de aquisição de conhecimento. Dissertação de mestrado - Escola de Engenharia, Universidade de São Carlos, São Carlos, 2003.

GIL, Antônio Carlos. Como elaborar projeto de pesquisa. São Paulo: Atlas, 2008.

GOLDRATT, Eliyahu M; COX, Jeff. A meta: um processo de melhoria contínua. 2.ed. São Paulo: Nobel, 2002.

GUERREIRO, Reinaldo. A meta da empresa: seu alcance sem mistérios. 2.ed. São Paulo: Atlas, 1999.

HENRIQUES JUNIOR Maurício Francisco et al.Manual de eficiência energética na Indústria de Cerâmica Vermelha. Rio de Janeiro: INT/MCTI, 2013. 28 p.

HEIZER, J.; RENDER, B. - Administração de Operações. LTC. 5a Edição. São Paulo, 1999.

INBRAS. Disponível em: http://www.inbras.com.br/aEmpresa. asp. 2015. Acesso em: 12 abr. 2015

LAW, Averill M.; KELTON, W. David. Simulation modeling and Analysis. New York: McGraw-Hill, 2000.

LORENÇO M. H. D. T. Simulação de operações preferenciais de ônibus urbanos em vias arteriais: uma metodologia para implantação de faixas exclusivas segundo o critério de tempo do usuário. Dissertação de mestrado, Programa de Engenharia de Transportes. COPPE. Universidade Federal do Rio de Janeiro, 1981.

MALHOTRA, Manoj ; RITZMAN, Larry P.; KRAJEWSKI, Lee. Administração de Produção e Operações. 8 ed. São Paulo: Pearson, 2009. 
PARAGON. Disponível em: $<$ http://www.paragon.com.br/padrao. aspx?apresentacao_content_ct_1685_2139_.aspx $>$. Acesso em: 27 ago. 2015.

PRADO, Darci Santos do. Usando o Arena em simulação. 3. ed. Belo Horizonte: Editora INDG Tecnologia e Serviços Ltda, 2014. PROJETO de Eficiência Energética nas Pequenas Indústrias de Cerâmica Vermelha do Brasil - ELLA. Panorama da Indústria de Cerâmica Vermelha no Brasil. Rio de Janeiro, jun. 2012.

SANTOS, P. S. Ciência e Tecnologia de argilas. 2. ed. São Paulo: Edgar Blucher, 2013. 1v.

SEBRAE; ESPM. Cerâmica vermelha: estudos de mercado. São Paulo: SEBRAE Nacional, 2008. Relatório Completo.

SCHOWB, M. R. V, Perspectivas de difusão do gás natural na industria brasileira de cerâmica vermelha. 2007 . 352f. Dissertação (Mestrado em Ciências em Planejamento
Energético)- Departamento de Engenharia, Universidade Federal do Rio de Janeiro, Rio de Janeiro, 2007.

SILVA, Edna Lucia da.; MENEZES, Estera Muszkat. Metodologia da pesquisa e elaboração da dissertação. 3. ed rev. e atual. Florianópolis: Laboratório de Ensino a Distância da UFSC, 2001.

SWAIT, Joffre. Simulação de engenharia dos transportes. COPPE / Universidade Federal do Rio de Janeiro, 1987.

VILAÇA, Márcio Luiz Corrêa. Pesquisa e Ensino: considerações e reflexões. Revista do Curso de Letras da UNIABEU, Nilópolis, v. 1, n. 2, p. 59-74, maio/ago. 2010. Disponível em: $<$ http://www.uniabeu.edu.br/publica/index.php/RE/article/ viewFile/26/pdf 23>. Acesso em: 1 set. 2014.

VALOR Logística Integrada. Disponível em: http://www. planetaferrovia.com/2013/02/valor-logistica-integrada.html. Acesso em: fev. 2015. 